\title{
Airport UPS Run in Parallel to Improve Power Supply Reliability and Energy Saving of Flight Information System
}

\section{Gang Yao*}

The Western Airport Group Co. Ltd., Xi'an Xianyang International Airport, Xi'an 710000, China

\begin{abstract}
In view of the security requirements of the power supply of the airport flight information system and the continuous improvement of the national energy conservation and environmental protection requirements, this paper proposes that the UPS power supply of the flight information system should adopt the mode of parallel operation. In addition, the terminal T2 of Xi'an Xianyang International Airport was successfully renovated and operated, which improved the power supply reliability, energy conservation and environmental protection of the flight information system. This paper comprehensively analyzes the cause and effect. Changing the operation mode of UPS effectively improves the power supply reliability of flight information system of Xi'an Xianyang International Airport and reduces energy consumption.
\end{abstract}

Keywords: UPS Parallel Operation; Power Supply Reliability; Energy Saving and Environmental Protection

With the rapid development of Xi'an Xianyang International Airport, the airport has higher and higher requirements on informatization, especially the guarantee of flight information system, which puts forward higher requirements on the power supply of the airport information system-backup power supply system (UPS).

With the constant improvement of the development and the national energy conservation and environmental protection requirements, the original power supply technology can't meet the requirements of the existing power quality and environmental protection. Therefore, it is necessary to re-examine a series of indicators such as reliable performance, maintainable performance and economized performance of the system, as well as the structure of the current information system power supply (UPS) and the space for sustainable development in the future.

\section{The necessity to change the system in terms of reliability}

\subsection{Reliability theoretical calculation and analysis}

The mean time without failure of parallel UPS is set as $\mathrm{MTBF}, \lambda=$ Failure rate, $\mathrm{MTBF}=1 / \lambda$.

Learn from system design:

\footnotetext{
Copyright (C) 2020 Gang Yao

doi: $10.18282 /$ fme.v2i1.818

This is an open-access article distributed under the terms of the Creative Commons Attribution Non-Commercial License

(http://creativecommons.org/licenses/by-nc/4.0/), which permits non-commercial use, distribution, and reproduction in any medium, provided the original work is properly cited.
} 


\begin{tabular}{|c|c|c|}
\hline UPS part & Failure rate & MTBF (hours) \\
\hline Rectifier & $\lambda$ rectification $=12.5 \times 10^{-6}$ & 80,000 \\
\hline Battery & $\lambda$ battery $=10 \times 10^{-6}$ & 100,000 \\
\hline Inverter & $\lambda$ contravariant $=14.28 \times 10^{-6}$ & 70,000 \\
\hline Bypass & $\lambda$ bypass $=1.43 \times 10^{-6}$ & 700,000 \\
\hline Parallel synchronous plate & $\lambda$ synchronous $=1.25 \times 10^{-6}$ & 800,000 \\
\hline Electric supply input & $\lambda$ electric supply $=2.97 \times 10^{-3}$ & 336 \\
\hline Repair rate & $\mu$ Repair rate $=0.5$ & 2 \\
\hline
\end{tabular}

When two UPS are redundant in parallel, that is, the load of two UPS is equally divided, the total load does not exceed the capacity of a single UPS.

$$
\lambda \mathrm{pn}=\frac{\mathrm{n}(\mathrm{n}-1) \times \lambda \mathrm{s}^{2}+(\mathrm{n} \times \lambda \text { synchronous })}{(2 \mathrm{n}-1)(\lambda)+\mu)}
$$

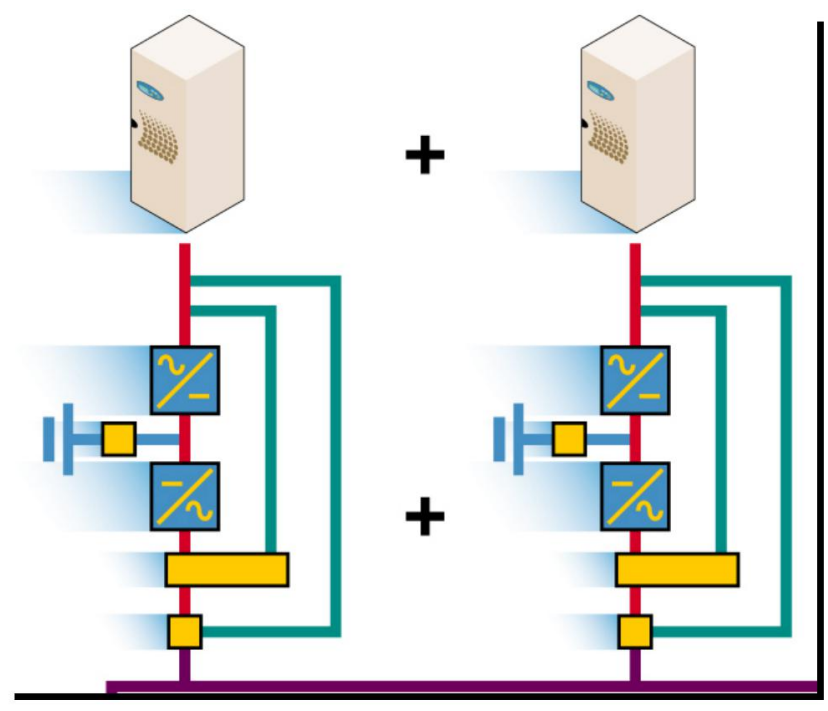

Figure 1. Two parallel UPS systems.

\subsection{The structural analysis of the system shown above}

In the series system, the main engine will be carried for a long time under the condition of no fault, and the standby machine will be in the state of no load for a long time. The battery cannot be activated by charge and discharge, resulting in uneven aging of the battery and the device itself of the two devices, which cannot effectively guarantee the reliability of the system when switching is needed.

In the parallel system, the two devices are both loaded and operated at ordinary times, while the battery is effectively maintained in time (modern UPS generally have automatic maintenance function) and the battery is activated in time, thus ensuring the basic functions of $\lambda \mathrm{m}=(\lambda$ rectification $+\lambda$ battery $+\lambda$ contravariant $)$

$$
\begin{aligned}
& \lambda \mathrm{p}_{2}=1.66 \times 10^{-6} \\
& \mathrm{MTBF}=600,000
\end{aligned}
$$

Therefore, the average failure rate of the two UPS systems is about 600,000 hours. the battery.

It can be concluded that the reliability of parallel system is much higher than that of tandem system.

The necessity to change the system from a green perspective

\subsection{The green concept of low harmonics in the input section}

At present, the input part of UPS adopts SCR 12 pulse rectifier or IGBT device, and its input Harmonic Current THDi can reach THDi $<5 \%$ when the UPS is working at full load. Generally, inverter adopts transistor or IGBT device, microprocessor control or DSP control. The general full load efficiency of the equipment is about 95\%-96\%. 
THDi refers to the fact that under normal working conditions, there is a large amount of high-frequency feedback from the rectifier to the upstream power supply, resulting in a high-frequency short circuit of the upstream power supply (power grid transformer, standby diesel generator or UPS, etc.). Problems include the pollution of the upstream power grid, the heating of the upstream cables, the switch tripping inexplicably, and the diesel generator must be expanded to work. Sometimes, in order to solve the pollution of the power grid, great efforts and costs have to be made to add additional filters to reduce the THDi. With modern technology, UPS's THDi has been able to reach $3 \%$ or less without further processing.

\subsection{The whole machine efficiency of the green concept}

Compared with the improvement of equipment efficiency, the efficiency is only increased from $90 \%$ to $95 \%$ in appearance. But the loss of equipment was reduced from $10 \%$ to $5 \%$.

For example, for the loss of two 200kVA UPS, set the efficiency of the old UPS at $90 \%$, the efficiency of the new UPS reaches $96 \%$.

Power consumption of the old UPS: $200 * 2 * 0.8 *$ $(1-90 \%)=32 \mathrm{~kW}$

Power consumption of the new UPS: $200 * 2 * 0.8 *$ $(1-95 \%)=16 \mathrm{~kW}$

Without considering the aging and other losses of long-running equipment and only discussing the improvement of efficiency of the two models due to the improvement of technology, the difference between the waste power consumption of the two models by comparison can be obtained.

The necessity to change the system in terms of cost savings

\subsection{Different in purchase prices}

\subsubsection{Different harmonic processing devices lead to different purchase prices}

UPS input parameters are often different due to device and structure differences. As discussed in the previous section, for the same 200kVA, THDi is approximately more than $30 \%$ when using 6 pulse technique; the current UPS rectifier is less than $5 \%$. Different rectification methods also have different technical indicators. Similarly, there are many different technologies that create different metrics.

With different technologies, if THDi is less than 5\% according to the conventional requirements of modern UPS, the input harmonic compensation of the new generation UPS will be omitted to save costs.

For example, the input compensation amount of a $200 \mathrm{kVA}$ UPS is about $100 \mathrm{~A}$, that is, the current purchase price is about 150,000 yuan/set. If there is more than one, the purchase cost will increase again.

\subsubsection{Different input power factors lead to different purchase prices}

The difference of power factor will directly cause the difference of the total current input, such as 6 pulse or 12 pulse rectifier UPS input power factor. There is no adjustment link between the traditional SCR 6 pulse or 12 pulse rectifier and the dc bus. Since there is no boost function, the voltage of the dc bus will directly affect the input power factor.

In general, the input power factor of a conventional SCR 6-pulse or 12-pulse rectifier will not be greater than 0.8 , and it will not be greater than 0.93 even if various compensations are added. However, due to the addition of compensation capacitance, other effects are not discussed here. But as a result, due to the dc voltage drop, starting charging the battery will cause a decline in the input power factor. The average UPS manufacturer will only provide the best power factor, not the worst power factor, which should be calculated during design or engineering applications. For example, in the UPS power supply for $200 \mathrm{ks}$ input output current SCR (silicon controlled rectifier) for 6 or 12 pulses rectifier UPS, input power factor is 0.8 (the parameters under the float charging voltage $13.2 \mathrm{~V}$ which are released by manufacturers); but in the actual charging, due to the dc voltage is very low at this time, the $12 \mathrm{~V}$ battery voltage is $11.4 \mathrm{~V}$ per $1.9 \mathrm{~V}$.

Substituting the above formula, it can be concluded that the power factor at this point is about 0.7 , which will be applied in the following example (when the battery is not completely put down).

Taking 200kVA UPS as an example, the efficiency of the whole machine is 0.93 . The dc power is $16 \mathrm{~kW}$ when charging.

The power factor of the old equipment is 0.8 
(floating charging state) and 0.73 (just at the beginning of the state of charge), while the power factor of the new equipment is 0.99 regardless of the dc state of the battery. It can be calculated that the input current of the old equipment is $330 \mathrm{~A}$ and the output current is $303 \mathrm{~A}$. For new equipment, the input current is $263 \mathrm{~A}$ and the output current is $303 \mathrm{~A}$.

At the beginning of charging, the maximum input current of the old device is $390 \mathrm{~A}$ and output current is $303 \mathrm{~A}$, while that of the new device is $288 \mathrm{~A}$ and $303 \mathrm{~A}$ respectively.

The different current leads to the different configuration equipment of the former stage, which saves the input cost.

Although the capacity of generation 2 UPS is the same as the output current voltage, the maximum input current is different due to different technical devices in the input part. That is, the corresponding upper end:

Transformer: the old 200kVA UPS must be equipped with $315 \mathrm{kVA}$ transformer; the new 200kVA UPS can be configured with 200kVA transformers.

Protection switch: the old 200kVA UPS must be equipped with 500A protection switch; the new 200kVA UPS can be configured with a $400 \mathrm{~A}$ protection switch.

Cable: the old 200kVA UPS must be equipped with $3 * 240$ square cable; the new 200kVA UPS can be configured with $3 * 150$ square cable.

\subsubsection{Different efficiency leads to different purchase prices for cooling air conditioners}

As discussed in the previous section, the efficiency difference between the old and new UPS is reflected in the difference in the calorie-value of two UPS - one is $32 \mathrm{KW}$ and the other is $16 \mathrm{~kW}$. At this point, the cooling capacity of air conditioners required is different, so the purchase price of air conditioners set for UPS is different.

\subsection{Differences in daily operating costs}

Daily operation refers to the cost of normal operation.

1) Due to the different efficiency of the old and new UPS, the power consumption is different, which is $16 \mathrm{~kW} / \mathrm{set}$, that is, 16 degrees/set per hour. If the electricity cost per kilowatt hour is 1 yuan, excluding the peak and valley difference, the annual electricity cost difference is 140,000 yuan/unit. The electricity cost of two UPS is different. The difference of cost of a little more than one year can afford another UPS.

2) As the calorification of the two types of UPS is different, the electricity consumption of air conditioners is also different. The electricity consumption of air conditioners is about $1 / 3$ of that of UPS.

3) The normal UPS must be replaced in years such as 5 years and 10 years. As the service life of the old UPS is longer, the price of spare parts of many manufacturers will be adjusted, and the price of the same parts may be higher due to stopping production and other reasons.

Through the above comparative analysis, the replacement of UPS not only increases the capacity of the equipment, but also greatly improves the reliability, availability, environmental protection and cost-effectiveness.

\section{References}

1. $\mathrm{Hu} \mathrm{Z}$, Deng L. UPS redundant connection and maintenance. Jiangxi Electric Power 2009; (4): 44-46. doi: CNKI:SUN:JXDL.0.2009-04-014.

2. Zheng Z, Ma X, Wang D. Reliability analysis of UPS system in power plant (in Chinese). Guangdong Science \& Technology 2009; (6): 97-98. doi: CNKI:SUN:GDKJ.0.2009-06-056. 